\title{
Language Used by Chinese Malaysian Students Studying at an Australian University
}

\author{
Chih-I LIAO \\ Monash University, Australia \\ chiivicky@gmail.com
}

Manuscript received 14 February 2020

Manuscript accepted 1 June 2020

*Corresponding author

https://doi.org/10.33736/ils.2350.2020

\begin{abstract}
In Australia, more than 33\% of total international students are Mandarin speakers. Mandarin has become a common language in the international student community in Australia. Speaking Mandarin is important while studying in an English-speaking country. This article explores Chinese Malaysian students' language proficiency and their language attitudes. Five participants were selected from an Australian university, and were interviewed. Their language proficiency was classified at five levels and in the questionnaire the participants were required to self-rate their proficiency for all the languages that they could speak. The findings show that three of the five participants preferred speaking English in Australia while the other two felt more confident of speaking Mandarin. All participants claimed that English and Mandarin are equally important for them when they are living in Australia. In contrast, the five participants' Bahasa Melayu proficiencies had largely decreased because of less practice and negative attitudes.
\end{abstract}

Keywords: Chinese Malaysians; language proficiency; language attitudes; Australia international students; Mandarin

\section{Introduction}

The number of international students in Australia has increased in recent decades, and Australian universities are increasingly culturally, ethnically and linguistically diverse. Since 2001, students from China have contributed the greatest proportion of total international students in Australia. In 2017 there were 799,371 international students in Australia; students from China comprise $28.9 \%$ of all international students in all education sectors (Australian Government Department of Education and Training [AGDET], 2017). The number of the international Malaysian students ranks fifth at $4.1 \%$. Figure 1 shows the top ten nationalities of international students in Australia and the percentages. According to Department of Education and 
Training, Chinese students consist of $28.9 \%$ of total international students, but Mandarin speakers not only come from China but also from other regions near China, such as Malaysia, Vietnam, Indonesia, Singapore, and Taiwan. The number of international students who might be Mandarin speakers could go up to $33 \%$ or even one third of all current international students (AGDET, 2017). It can be said that one out of every three international students in Australia is a Mandarin speaker.

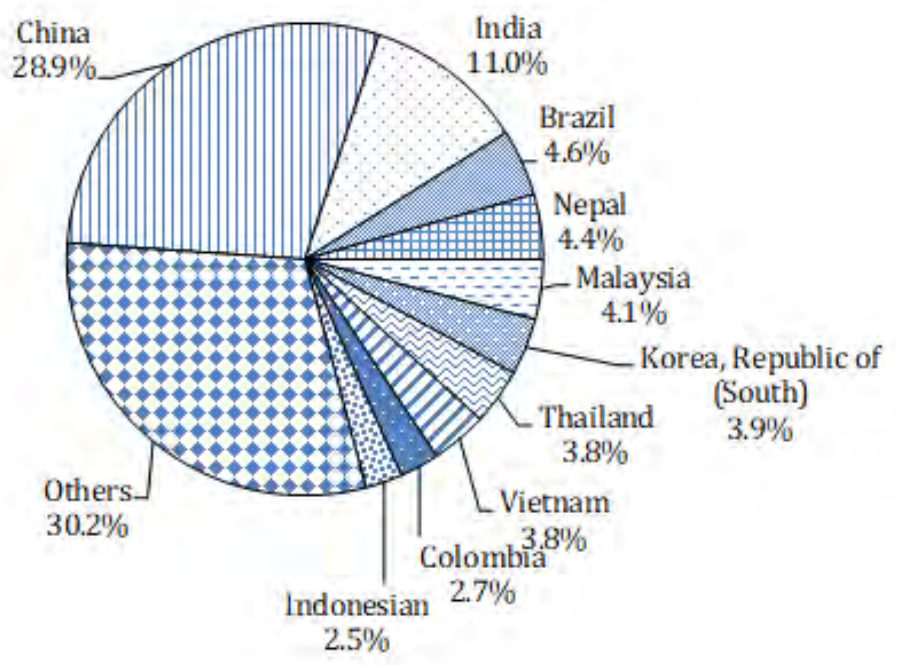

Figure 1. Top 10 Nationalities of international student enrolments in 2017 (Diagram created by author based on data from Australia Government Department of Education and Training)

Chinese Malaysian international students were selected because Chinese communities in Malaysian are entering a new sociolinguistic phase (Wang, 2010). The language choice and language attitudes of young Chinese Malaysians showed that Mandarin and English are better accepted than other languages in this generation whether young people stay in Malaysia or live in Australia. In Malaysia, the younger Chinese Malaysians have been raised in a multicultural society while their parents and grandparents speak various Chinese languages in Chinese communities (Coluzzi, 2017b; Ting \& Chang, 2008; Wang, 2017). The younger generation appears to prefer speaking Mandarin and English, and they seem to favour these two languages (Wang, 2010; Wang \& Chong, 2011). The national language of Malaysia is Bahasa Melayu. Compulsory subjects and examinations in Bahasa Melayu and English have forced Chinese Malaysian students to develop proficiency in both languages. In general, young Chinese Malaysians are capable of speaking Bahasa Melayu, English and at least one of the Chinese languages (depending on their family language policy) (Abidin, Pour-Mohammadi \& Ooi, 2011; Wang, 2017) before they come to study in Australia.

Despite different reasons for choosing to study in Australia, the main purpose of overseas study is to improve students' English skills. Assisting children to 
gain a higher degree is seen as good parenting in Chinese culture. Chinese parents put great effort into choosing good universities to offer their children better quality education and to improve their employment opportunities (Bodycott, 2009). Young Chinese Malaysians are encouraged to go overseas for study.

International students tend to have communication and social difficulties and they may struggle both academically and socially (Sato \& Hodge, 2009). This research takes a sociolinguistic approach to explore the language use of Chinese Malaysian international students who are currently studying in Australia. Through sharing a similar background, language also supports the sense of belonging and forms social bonds (Coulmas, 2013).

Language shift is understood as some demonstrable change has occurred in the pattern of habitual use (Fishman, 1972). When young Chinese Malaysians speak less heritage (Chinese) language and prefer Mandarin or English, Chinese in Malaysia are experiencing the language shift. The language use by international Chinese Malaysian students may reflect shift among generations in Chinese communities in Malaysia, this research focuses on changes of international Chinese Malaysian students' language proficiency while they study in Australia.

\section{Research Background}

In the 1920s, Mandarin was promoted in schooling as the main language in China. This change influenced the diasporic Chinese communities. The Chinese schools in Malaysia changed their teaching programs from various Chinese languages to Mandarin as a response to the authority of China (Sam \& Wang, 2011). The increasing number of Mandarin speakers threatened the existence of other languages, and other Chinese ethnic languages were gradually phased out (Wang, 2012).

Young Chinese Malaysians aged 20 to 30 are now living in a transition stage, with a shift of language use. Most young Chinese Malaysians appear to have different language preferences compared with their parents and grandparents. Middle-aged Chinese Malaysians and the elderly Chinese Malaysians speak Chinese ethnic languages, such as Hokkien, Hakka or Cantonese as these three languages are mainly spoken in Chinese communities in Malaysia. Bahasa Melayu, English and Mandarin are the medium at school. When Chinese Malaysians study in Malaysia, they study Bahasa Melayu and English; and some of them keep other Chinese languages at home (Ting \& Chang, 2008). Chinese Malaysian students come to Australia to improve their English skills and they like to gain international experiences. As Chinese students coming from mainland China comprise $28.9 \%$ of the total international students in Australia, the language proficiency of Chinese Malaysian students is affected by the primacy of Mandarin.

\section{The Chinese in Malaysia}

In Southeast Asia, the term "Chinese" refers to those whose ancestors migrated from South China (Tan, 2000). The history of Chinese in Southeast Asia can be traced back to the fifteenth century. Chinese immigrants in the Malay Peninsula were 
mostly from Southeast China: Fujian and Guangdong Provinces (Tan, 2004). The large-scale Chinese immigration contributed to the economic and cultural development in Malaysia. Hokkien, Hakka and Cantonese are the three dominant languages in these areas; other languages are Teochew, Hainanese and other minor languages. Chinese Malaysians rely heavily on ethnic group distinctions that are originally based on the geographical area from which their ancestors came. Speaking any of the Chinese languages in Malaysia helps them to strengthen their sense of belonging to a particular group.

By 2015 the population of Chinese Malaysian was 6.64 million; it constitutes $21 \%$ of the total Malaysian population (Department of Statistics, Malaysia, 2015). Through gradual assimilation into the host country and more contact with other groups, Chinese Malaysians adopted Malay, English and indigenous cultures. As Malaya moved toward independence from Britain there was a period of disturbance; Chinese residents in Malaysia began to define themselves as local (Carstens, 2005). The term "Chinese Malaysians" is preferred to "Malaysian Chinese" as many of them stress the local cultural and political identities (Tan, 2000, 2004).

In the 1980s, Cantonese television programmes swept over and filled in Malaysian Chinese life (Sim, 2012). Cantonese can be seen as the fashion or it is a very popular cultural medium even in an unwavering Hakka community. The Chinese who are not Cantonese speakers may not always have understood the language, but they seem to enjoy watching Cantonese videos and following the style of Hong Kong life . Cantonese became a trendy language, and the local Malaysian television station started to produce shows in Cantonese. Cantonese was the sole language for the Chinese Malaysian audience until a Hokkein TV channel, Hua Hee Dai, started to broadcast in Malaysia in 2007 . When TV programmes made by Hong Kong were the only source imported to Malaysian Chinese communities, the participant's skills and knowledge influence their language use. The young Chinese Malaysians may maintain their Cantonese speech but show less motivation to keep it. They enjoy Hollywood movies, Korean culture and Manga.

Malaysia is facing globalised economic development. The authorities have to admit that English now has a place in the education system (Schiffman, 2010). In the context of a sociolinguistics realignment framework, the language situation in Malaysia can be divided into three periods: the colonial period, after independence, and the prediction for the future. In the past, English was a preferred and highstatus language, and English schools remained the first choice for wealthy Chinese families. However, with independence the new government promoted Bahasa Melayu as the national language, thereby changing the language hierarchy in Malaysia. Mandarin has become more important in the Chinese communities (Wang, 2010). Moreover, China has become the fastest growing economy in the world and the standard Chinese, Mandarin, has extended its influence on more countries. Many other Chinese speech groups in overseas Chinese communities have been threatened, and they are facing the challenges of losing their ethnic culture. In the Chinese communities of Malaysia, the languages have been realigned: English and Mandarin are promoted to high languages and other Chinese ethnic languages are at the bottom of the language status (Wang, 2010). 


\section{Malaysian International Students}

The history of Malaysian students studying abroad can be traced back to the Colombo Plan in the 1950s. The Colombo Plan is a regional organisation which was set up to promote economic cooperation and social development among countries in the Pacific-Asia region. The Colombo Plan was established on 1 July 1951 by Australia, Canada, India, Pakistan, New Zealand, Sri Lanka and the United Kingdom and currently has expanded to include 27 member countries. Malaysia joined the Colombo Plan in 1957. From this time on Malaysian students came to Australian to study. By the mid-1960s, over 500 Australian experts had completed about 650 assignments in Colombo Plan countries. Over $40 \%$ of Australian personnel contracted under the auspices of the programme went to Malaysia (Oakman, 2010). A distinguished Malaysian student, Mariam Manaf, was able to study in 1963 at the newly-founded Monash University through receiving a Colombo Plan award. The Colombo plan still continues to grow and now includes more countries and supports more international students. In 2001, on the 50th anniversary of the Plan, a Malaysia-Australia Colombo Plan Commemoration (MACC) scholarship program offered more opportunities to exchange students between the two countries.

Although there are no current data to prove that international students from Malaysia are all Chinese Malaysians, it can be argued that due to the importance of education in Chinese culture and the Malaysian authorities' tendency to protect Malay students in their homeland, it is assumed that Malaysian students who come to Australia to study are mostly Chinese Malaysians. The relationships among ethnic groups has always been a sensitive topic in Malaysia. Chinese Malaysians need to build their education system to pass down Chinese culture and languages; and the limited opportunities for applying to local universities has caused Chinese Malaysian students to study in other countries. This matter has been discussed in the media which shows that it remains a matter of public discussion.

The use of Mandarin in Chinese schools in Malaysia has helped to maintain the importance of linguistic identity in Chinese communities. The resistance of Malay education resulted in the preferential placement given to Malays at public universities. Many Chinese students had to continue their education at overseas universities where Bahasa Melayu is not necessary (Ha, Koh, \& Chng, 2013). The BBC reported two students' stories on September 2, 2013 (Pak, 2013): one was a Chinese, Mr. Soh, the other one was Ms. Hanie, who was a Bumiputera (meaning Indigenous peoples in Malay). They both applied to government-funded medical universities, but only Ms. Hanie was accepted although Mr. Soh had higher scores in the high school exams. The BBC report stated that Mr. Soh considered leaving due to his disappointment with the education system. This public discussion raised the need for education reform. The Deputy Education Minister P. Kamalanathan explained that Chinese Malaysian applicants had a higher success rate than Bumiputera and Indians. Chong Sin Woon and other Chinese Malaysian students argued that there had been an unfair platform in university entrance for Bumiputera and other ethnics. 
Table 1

International student enrolment in Higher Education in 2017 by Australian State/Territory

\begin{tabular}{lcccccccccc}
\hline Nationality & NSW & VIC & QLD & SA & WA & TAS & NT & ACT & NAT & Total \\
\hline China & 51,230 & 45,076 & 14,889 & 8,461 & 4,973 & 2,155 & 132 & 6,975 & 0 & 133,891 \\
India & 15,733 & 24,432 & 7,184 & 2,147 & 3,426 & 520 & 251 & 683 & 0 & 54,376 \\
Nepal & 14,529 & 3,533 & 1,718 & 526 & 610 & 128 & 362 & 75 & 0 & 21,481 \\
Vietnam & 5,195 & 6,344 & 1,400 & 856 & 868 & 153 & 57 & 219 & 0 & 15,092 \\
Malaysia & 2,263 & 6,256 & 2,027 & 1,353 & 1,857 & 612 & 11 & 301 & 0 & 14,680 \\
Pakistan & 4,690 & 4,045 & 798 & 263 & 855 & 105 & 67 & 177 & 0 & 11,000 \\
Indonesia & 2,963 & 4,291 & 731 & 247 & 699 & 20 & 38 & 304 & 0 & 9,293 \\
Hong Kong & 2,665 & 2,187 & 1,847 & 1,083 & 756 & 111 & 7 & 232 & 0 & 8,888 \\
Sri Lanka & 872 & 5,275 & 623 & 187 & 386 & 75 & 24 & 124 & 0 & 7,566 \\
Singapore & 1,325 & 2,392 & 1,309 & 497 & 1,233 & 264 & 2 & 192 & 0 & 7,214 \\
Others & 23,938 & 17,701 & 13,288 & 3,220 & 5,544 & 895 & 492 & 1,912 & 1 & 66,991 \\
\hline Total & 125,403 & 121,532 & 45,814 & 18,840 & 21,207 & 5,038 & 1,443 & 11,194 & 1 & 350,472 \\
\hline
\end{tabular}


Possibly for this and other reasons, it seems that Chinese Malaysian students often pursue tertiary studies overseas in countries such as Australia. Table 1 shows numbers of international students studying in Higher Education in each state of Australia in 2017. Table 1 shows that a majority of international Malaysian students stayed in the State of Victoria, that is, 6,266 out of 14,680 international Malaysian students.

\section{Methodology}

This research examines the language use of international Chinese Malaysian students studying in an Australian university. Since Victoria has the greatest number of international Malaysian students, this case study was located in one of the large universities in Melbourne. A case study allows researchers to explore the meanings of real-life events in their social context (Yin, 2014). This research was based on small group behaviour. The case study method could successfully provide a completed structure, and describe a contemporary phenomenon based on our participants' real life in Australia.

The first section of the questionnaire elicited participants' background information, including the birthplace, religion and the ethnicity of their paternal and maternal relatives. The places they have lived, and their home environments may affect language usage, proficiency and choices. The participants' language choices offered an overview of language use in Malaysia and their language choices also demonstrated the functions of each language.

The second part of the questionnaire was intended to discover what languages they can speak and their self-perceived level of proficiency in speaking, reading and writing the languages. Following the research model of Gal (1979) for Oberwart, Austria, participants were required to self-rate their proficiency in each language in five levels, from 1-weak to 5-excellent. The research of language proficiency is based on the Interagency Language Roundtable (ILR) scale which is a set of descriptors of abilities to communicate in a given language. The Interagency ILR scale is a standard grading scale for language proficiency in the United States Federal-level service. Language proficiency is on the scale of $0-5$, it can also be $0+$, $1+, 2+, 3+$, or $4+$, with 11 possible grades in total. I designed my scale by modifying ILR and Gal's (1979) method. There are five levels of language proficiency in this research. Five levels of language proficiency are recognised (excluding level 0 which means no knowledge of the language). Level 1 is elementary proficiency. Level 5 language proficiency is that of a native speaker. Level 4 speakers are able to speak quite fluent language and can be generally understood. Level 3 speakers are good in speaking and may make a few errors or hesitate when they speak but it normally does not affect interlocutor understanding. Level 2 speakers are below the intermediate level and may not be able to communicate well with others. They have limited knowledge of the language, usually present long pauses in talking and always need assistance in translation when reading documents. The lowest level is 1 for very weak language proficiency. Level 1 speakers may be be able to say a complete sentence. 
The last part of the questionnaire was an open discussion: there were seven questions which would be asked by the researcher and the participants could talk honestly. The questions included the feelings of speaking a specific language and the importance of using English or Mandarin in Malaysia and Australia.

Data were collected using a short questionnaire and semi-structured interview. In the last section of the questionnaire, there are open-ended questions for the semi-structured interviews. Participants could describe their language background and their feeling about speaking those languages. Interviews provide opportunities for in-depth probing and the researcher could be more successful with obtaining response to open-end items (Wiersma \& Jurs, 2009). Moreover, the semistructured interviews produced an open discussion which allowed unexpected findings. This study attempts to interpret the lived experience of international Chinese Malaysian students.

Qualitative data were analysed by using Interpretative Phenomenological Analysis (IPA) which is based in phenomenology and seeks to explore participants' understandings of their lived experiences (Smith, Flowers, \& Larkin, 2009). As an analytic approach, IPA begins with reading and re-reading transcribed data which is then coded using marginal notes. These initial codings are used to build emergent themes that are then constructed into overarching themes. Direct quotations from participants are used to capture the participants' voices. All participants have been given pseudonyms.

\section{Findings}

The findings from this study will cover the following: language proficiency, language choice and language attitudes. Each section introduces participants' language behaviour and their identification for languages. The participants' background information are shown in Table 2.

Table 2

Background Information on Participants

\begin{tabular}{|c|c|c|c|c|}
\hline Name & Birthplace & Languages & $\begin{array}{l}\text { Language spoken } \\
\text { at home }\end{array}$ & $\begin{array}{l}\text { Dominant language } \\
\text { (self- assessed) }\end{array}$ \\
\hline$J$ & $\begin{array}{l}\text { Tawau, } \\
\text { Malaysia }\end{array}$ & $\begin{array}{l}\text { Mandarin } \\
\text { English } \\
\text { Cantonese } \\
\text { Malay } \\
\text { Hakka }\end{array}$ & $\begin{array}{l}\text { Mandarin(father) } \\
\text { Mandarin, English, Hakka, } \\
\text { Cantonese (mother) }\end{array}$ & Mandarin \\
\hline$A$ & $\begin{array}{l}\text { Kuala Lumpur, } \\
\text { Malaysia }\end{array}$ & $\begin{array}{l}\text { Mandarin } \\
\text { English } \\
\text { Cantonese } \\
\text { Malay } \\
\text { Hokkien }\end{array}$ & Mandarin & Mandarin \\
\hline M & $\begin{array}{l}\text { Kuala Lumpur, } \\
\text { Malaysia }\end{array}$ & $\begin{array}{l}\text { Mandarin } \\
\text { English } \\
\text { Cantonese }\end{array}$ & English, Cantonese & English \\
\hline
\end{tabular}




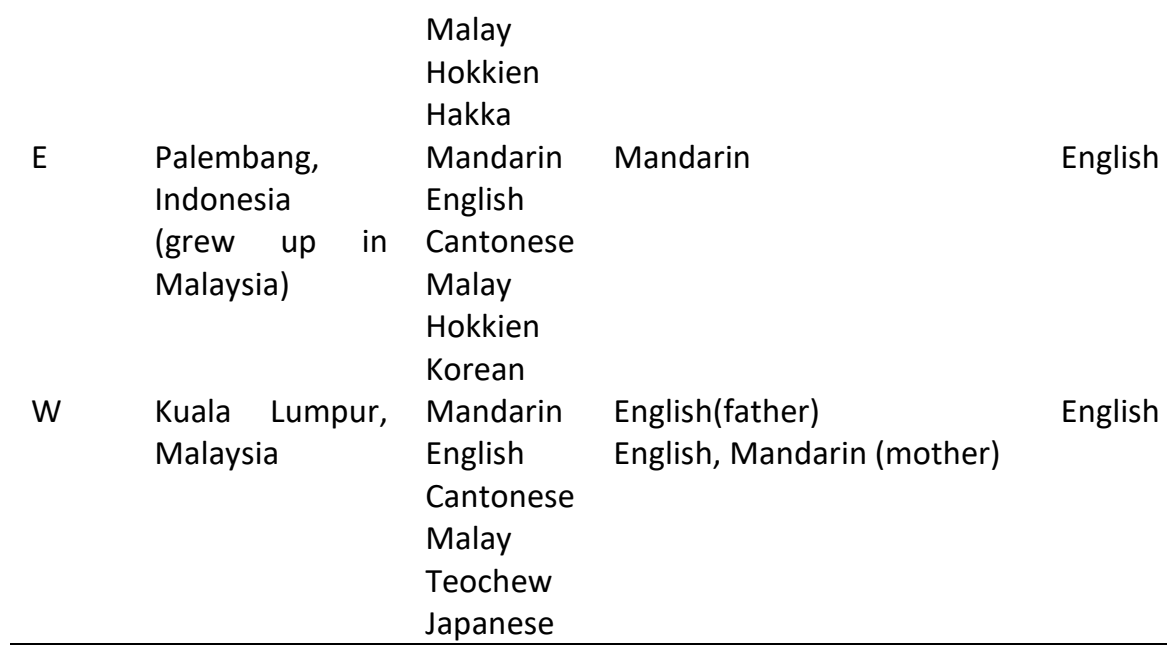

\section{Language Use}

All participants who were studying in Australia at the time of the study were born or grew up in Malaysia. They were aged 21 to 23 and have stayed in Australia from six months to two years. All of the participants had hesitation in answering the question: What is your first language? They acquired several languages during their childhood; various languages exist in the family which is the first domain they come into contact with. The common languages among the five participants are Mandarin, English, Bahasa and Cantonese. Besides these, they also speak Hokkien, Hakka and Teochew, showing the various languages in the Chinese community in Malaysia.

Table 3

Participants' proficiency in speaking various languages

\begin{tabular}{|c|c|c|c|c|c|c|c|}
\hline & Mandarin & English & $\begin{array}{l}\text { Bahasa } \\
\text { Melayu }\end{array}$ & Cantonese & Hokkien & Hakka & Others \\
\hline $\mathrm{J}$ & 5 & 4 & 3 & 3 & $X$ & 4 & $X$ \\
\hline A & 5 & 4 & 3 & 3 & 2 & $x$ & $x$ \\
\hline$M$ & 3 & 5 & 3 & 4 & 2 & 2 & $x$ \\
\hline$E$ & 4 & 5 & 3 & 1 & 4 & $x$ & $\begin{array}{c}3 \\
\text { Bahasa } \\
\text { Indonesia } \\
1 \\
\text { Korean }\end{array}$ \\
\hline W & 4 & 5 & 4 & 3 & $x$ & $x$ & $\begin{array}{c}1 \\
\text { Teochew } \\
3 \\
\text { Japanese }\end{array}$ \\
\hline
\end{tabular}

All participants in this study are capable of speaking Cantonese; four of them assessed themselves to be fluent (see Table 3). Cantonese has been an influential 
language in Kuala Lumpur (KL, the capital city of Malaysia). It was accepted as the lingua franca across various ethnic groups (Tan, 2000).

Cantonese retained its high status for a relatively long period even after the Federation of Malaysia achieved its independence in 1957. The spread of Guangdongese (people who live in or have migrated from Guangdong Province of China to overseas) and their accompanying cultures and languages to overseas Chinese communities was not by accident. Guangdong Province was one of the earliest divisions of China which had extensive trade networks with other countries since the sixteenth century (Yow, 2013). As Cantonese is a powerful language and Cantonese speakers are the majority in Chinese communities in KL, young Chinese Malaysians from KL are assumed to have Cantonese proficiency. The other minor Chinese languages in Malaysia such as Hainanese, Fuzhou and Teochew have shifted to either Cantonese or to Mandarin (Wang, 2010, 2012). All the participants emphasised that it is necessary to speak Cantonese in the Chinese community in KL; Cantonese dominated all kinds of social gatherings and business activities. High school students would switch to Cantonese secretly although school did not allow them to do so.

Participant A: 我班上二十六位學生，只有兩人是馬來人，其他全部都是華人，華人都 講廣東話.

(There were twenty-six students in my class, all were Chinese except two of them who were Malay. Chinese students always spoke Cantonese)

Participant E: 我哥哥現在在 KL 工作，他是一名 sales，他去 client 那邊，client 問他你 會不會講 Cantonese? 他說可以講，但不是 advanced，client 說你要學，這是一條 unspoken rule.

(My brother works in KL. He is a salesman. When he visited his client, the client asked him whether he could speak Cantonese. He said yes, but not at an advanced level. The client said "You must learn, this is an unspoken rule") One of the significant factors for the speedy spread of Cantonese is the mass media. Participants who were not from a Cantonese speaking family acquired Cantonese from TVB. Television Broadcasts Limited (TVB) was one of many Chinese Malaysians' shared memories. TVB is a commercial television station based in Hong Kong, which commenced broadcasting in 1967. It was the first wireless television station in Hong Kong and today it runs five free channels. TVB's headquarters is the largest commercial television production centre in Asia, their television programmes are available in Mainland China, Taiwan, Macau, the United States, United Kingdom, Canada, Australia, Ireland, New Zealand, Thailand, Malaysia, and Singapore. As long as there are Chinese in a region, there is TVB.

Participant J: 我的廣東話是看電視學的，大概七歲吧。

(I acquired Cantonese via TV programs since I was about seven)

Participant A: 我家是講華語的，我廣東話從 TVB 學的，還有跟朋友講就學囉。 
(We speak Mandarin at home, but I gained Cantonese from TVB. Many of my friends speak Cantonese too)

Participant J was born in Sabah State and raised in one of the cities in Sabah (Tawau), where she was surrounded by Hakka speakers. She has learnt Cantonese from TV programs and she enjoyed speaking Cantonese. With Cantonese speech, she could talk about TV programs with friends. When she studied in a university in $\mathrm{KL}$, there were numerous occasions allowing her to practise it. Participant $\mathrm{A}$ stated that many Chinese families watched TVB and it was the most important source for learning Cantonese. They did not plan to learn the language, but Cantonese was too prevalent.

Three participants reported that they were able to speak Hokkien; two could speak Hakka and only one spoke quite weak Teochew. Although Hokkien, Hakka and Teochew were included in this research, all participants showed less interest in those languages.

\section{Best proficiency in English and Mandarin}

Two participants in this survey ranked their Mandarin at level 5 (as the native speaker) and two others ranked their Mandarin proficiency at level 4 (fluent). Participant $M$ was the only one who graded her Mandarin speaking at the intermediate level due to her later acquisition of the language.

In terms of English speaking, all participants showed great confidence: fluent and excellent were ticked. Interestingly, two participants, $J$ and $A$, rated themselves as excellent Mandarin speakers but only ranked themselves at four in English. They considered Mandarin as their dominant language and it is the language they can express themselves best rather than English. The other participants preferred English as their dominant language. The results showed that both English and Mandarin are a significant part in Chinese Malaysian students' overseas study.

\section{Decrease in Bahasa Melayu Proficiency}

In spite of the language policy in Malaysia, Bahasa Melayu is the compulsory subject in all educational institutions. Chinese Malaysian students in this study do not appear to have very high proficiency in the national language of Malaysia. They had less contact with Malaysian groups and few opportunities to speak Bahasa Melayu in either Chinese Malaysian communities or Australia. Five participants reported that their proficiency in Bahasa Melayu has largely decreased since they arrived in Australia. There was no motivation for them to keep up Bahasa Melayu.

\section{Japanese and Korean}

Japanese and Korean popular cultures have attracted many Chinese Malaysians of the young generation to learn those languages. Korean pop culture or "K-Pop" boom started since the late 1990s, and the popularity of K-pop has rapidly spread in many countries. The Korean wave including pop stars, music and television dramas is 
considered to be a trend (Choi \& Maliangkay, 2015). The influences of mass media have boosted the spread of Japanese and Korean in areas of Asia. The young Chinese Malaysians watch Korean series or follow their favourite singers through the social media. They also try to read or understand Korean languages, but those Korean pop culture followers did not change their linguistic identities. Participant $W$ has medium Japanese proficiency and participants $M$ and $E$ are familiar with some basic Korean words. They all claimed that they started learning the languages because of pop culture.

\section{Language Proficiency Change}

All participants expressed positive attitudes to English after staying in an Englishspeaking country for more than six months. The great quality of education leads them to improve their English skills in writing and listening. Although English is also one of the common languages in Malaysia, studying in Australia offers a more efficient way to learn English.

Bahasa Melayu is an example of a language that participants appeared to lose. Despite all five participants rating their proficiency at level 3 in Bahasa Melayu, they hardly spoke and read Bahasa Melayu in Australia. The foreign environment leads to degeneration of their Bahasa Melayu proficiency. The participants concluded that they would either stay in Australia or go back to Malaysia to look for a job. Bahasa Melayu is no longer necessary in their life as long as they can keep some basic words.

\section{Improved Mandarin Proficiency}

Mandarin is the lingua franca in the international Chinese student community in Melbourne. Mandarin seems to be the chosen language when two Chinese students meet each other. Moreover, with the increasing number of fluent Mandarin speakers in Malaysia, international Chinese Malaysian students are stimulated by the prevailing trend of speaking Mandarin in Australia. As international students may suffer from loneliness, many of then the company of students from similar backgrounds (Briguglio \& Smith, 2012). A non-Mandarin Chinese Malaysian student may be inspired by another Malaysian Mandarin speaker who comes from either Malaysia or other overseas Chinese communities (China, Taiwan, Hong Kong, Singapore or Indonesia). One participant in this research had weak proficiency in Mandarin when she was in Malaysia, but she was excited to report that her Mandarin has improved in Melbourne.

Participant M: 我的華語進步啦! 我在這裡講很多華語耶! 我跟他們(其他受訪者:馬來 西亞華人)講華語，我有其他朋友他們也喜歡講華語，有時候在學校見到你(作者:臺灣 籍)，我也會跟你講華語，現在多很多機會講!

(My Mandarin speaking is getting better. I speak Mandarin to them [other participants, from Malaysia]. Some of my friends out of school like to speak Mandarin as well ..., or sometimes I meet you [the researcher, from Taiwan] 
on campus and we speak Mandarin. I speak Mandarin more frequently here than I did in Malaysia)

According to my observation, a conversation among Chinese Malaysian students is always bilingual: English and Mandarin. However, a person who prefers Mandarin can always lead the conversation to Mandarin speech. During the interview, participants $E$ and $M$ talked in English because of $M$ 's limited Mandarin. They included some Mandarin sentences for better explanation. When participant A joined the conversation, he preferred speaking Mandarin to all his Chinese Malaysian friends. He could always divert the conversation to mostly Mandarin, and the others were pleased to follow. If $\mathrm{M}$ had trouble in understanding Mandarin, they explained in English to her and brought the conversation back to Mandarin until the next language switch. The findings in this research show that Mandarin has been chosen as the dominant language in the Chinese Malaysian students' group in Australia.

\section{Language Attitudes}

Language attitudes are dominated by powerful ideological positions. People in dayto-day living are apparently not conscious of the influence of those ideological positions, instead, they tend to accept common sense (Garrett, 2010). Language attitudes are hard to describe as an organised or measureable matter. Language attitudes need to be demonstrated through actual behaviour; participants' responses and opinions related to language varieties are even more significant. In this research, attitudes towards each language are defined in terms of the language's functions and participants' motivation towards learning language.

There is a formula for Chinese Malaysians people speaking Malay, specialising in specific domains and interlocutors. They use it when they need to talk to Malay people. The negative language attitude towards Bahasa Melayu is the significant factor in the international Chinese Malaysian students' loss of speaking proficiency in Bahasa Melayu. In contrast, English is appreciated in either Malaysia or Australia; international Chinese Malaysian students showed more interests in improving their English skills. Both Bahasa Melayu and English are compulsory in Malaysia, Bahasa Melayu is the national language of Malaysia which replaced English as the official language after the country gained independence from the British Empire. Chinese Malaysians have opposite attitudes towards both languages. Bahasa Melayu proficiency is not encouraged by Chinese Malaysian parents, and they do not expect their children to get good results in Bahasa Melayu.

我爸爸告訴我，馬來話只要 pass 就好 (A)

(My father told me, only pass the BM course study. It is good enough)

All participants' parents believed that English should be the priority of education, as well as Mandarin. Mandarin has become a lingua franca in Chinese communities in Malaysia . Mandarin is a necessary skill for maintaining networks, and it is likely to replace all Chinese ethnic languages in Chinese Malaysian communities in the near 
future. In order to enhance children's competitiveness, many Chinese Malaysian parents have adopted the English and Mandarin bilingual family communication patterns. Supporting children to study overseas suggests that all participants' parents have positive attitudes and expectations in English. It is Mandarin at home, and English in education.

In this study, five participants believed that English and Mandarin are equally important in Malaysia and Australia. The participants reported that they speak both Mandarin and English almost every day, even though Australia is basically an Englishspeaking country. In general, in Melbourne, they receive English education in the university, but they are surrounded by Mandarin speakers. Participant W mainly spoke in English during the interview. She made quite a valid point about the importance of Mandarin to Chinese Malaysians students in Australia.

Participant W: If you study in Australia, of course, English is the most important language. But talking about surviving here, you definitely need Mandarin.

According to Participant W, acquiring Mandarin is beneficial in Australia, for convenience and for social activities. Five participants claimed that they would continue to keep English and Mandarin for their later life whether they choose to stay in Australia or return to Malaysia.

\section{Discussion}

By combining insights from language use and language attitudes among international Chinese Malaysian students, this study shows that not only English is a required skill when studying in Australia but Mandarin. The five participants reported their good language proficiency in both Mandarin and English, and these two languages are needed and spoken in their daily life in Australia. The findings show that Chinese Malaysian students in Australia are willing to speak Mandarin when they have chance to do so. One of five participants has proventhe importance of having Mandarin proficiency in Australia. Her Mandarin speaking proficiency has been improved during overseas experiences.

Positive feelings refer to a language which is often encouraged by the role it plays as a marker of a desired group. Negative language attitudes mean having a rejected identity (Saville-Troike, 2003). Mandarin remains in the highest prestige in Chinese communities in Malaysia and Australia. Although speaking Mandarin is slowly causing other Chinese ethnic languages to decline in usage, all participants enjoy having Mandarin conversation with other overseas Chinese students. In contrast, all participants stop using Bahasa Melayu since they left high school. It is just a subject for Chinese Malaysian students (Coluzzi, 2017a). They have no interest and they are not encouraged to keep Bahasa Melayu (How, Chan \& Abdullah, 2015) Such attitudes decrease their proficiency of Bahasa Melayu. The five participants rated their Bahasa Melayu proficiency at level 3 in the questionnaire. The fair Bahasa Melayu abilities only allow them to chat to a few Malaysian friends and fill in official documents when they return to Malaysia. They showed little worries about not having advanced Bahasa Melayu proficiency in their future planning. 
Although five participants have good Cantonese proficiency and they identify Cantonese as a social language in Malaysia and they sometimes switch between Mandarin and Cantonese in Australian Chinese communities. However, Mandarin, as a globally employed language, has blurred linguistic distinctions within Chinese communities in Malaysia. The number of Cantonese, Hakka and Hokkien speaker is falling (Wang, 2010, 2012). All participants agreed that the process of replacing Cantonese with Mandarin is undergoing. They prefer speaking Mandarin as it is more useful, taking into consideration social factors, education and globalisation.

This study focussed on the changes in language proficiencies, comparing language use of five participants in Malaysia and Australia. Five participants present a similar result: the improvement in English and gradual loss of Bahasa Melayu. Specifically, English obviously is the primary language on campus and almost everywhere in Australia. The participants emphasise that their English writing have improved by academic training. On the other hand, few opportunities and unenthusiastic attitudes cause their spoken proficiency in Bahasa Melayu to decrease.

As there are more than $33 \%$ of Mandarin speakers among the total international students in Australia, this offers many opportunities for the use of Mandarin. One of the five participants in this research reported getting on well in Mandarin. Two participants rated themselves as fluent in Mandarin, other two participants reported that their Mandarin proficiency was excellent, at native speaker proficiency level. Their proficiency in Mandarin remained at a similar (high) level as they already had excellent Mandarin speaking skills before they came to Australia. They need to speak Mandarin to survive while English is for study. Mandarin enalbes Chinese Malaysian students to build a network in Australia.

The findings of this study affirm the decreasing function of Chinese ethnic languages and the more popular use of Mandarin as today's lingua franca in the Chinese community in Malaysia. An implication of this study is that the language proficiency and linguistic choices of the younger generation of Chinese Malaysians are influenced by societal changes in Malaysia. There is a demonstrable language shift in Chinese communities that needs to be recognised and accommodated in planning in Malaysia.

\section{References}

Abidin, M. J. Z., Pour-Mohammadi, M., \& Ooi, C. L. (2011). The reading habits of Malaysian Chinese university students. Journal of Studies in Education, 1(1), 1-13.

Australian Government Department of Education and Training (2017). International student data. Retrieved from https://internationaleducation.gov.au /research/International-Student-Data/Documents/MONTHLY\%20SUMMA RIES/2017/Dec\%202017\%20MonthlyInfographic.pdf

Briguglio, C., \& Smith, R. (2012). Perceptions of Chinese students in an Australian university: are we meeting their needs? Asia Pacific Journal of Education, 32(1), 17-33. 
Bodycott, P. (2009). Choosing a higher education study abroad destination: What mainland Chinese parents and students rate as important. Journal of Research in International Education, 8, 349-373.

Carstens, S. A. (2005). Histories, cultures, identities: Studies in Malaysian Chinese worlds. Singapore: Singapore University Press.

Choi, J., \& Maliangkay, R. (Eds.). (2014). K-Pop-The international rise of the Korean music industry. Milton Park, Abingdon: Routledge.

Coulmas, F. (2013). Sociolinguistics: The study of speakers' choices (2nd ed.). New York, NY: Cambridge University Press.

Coluzzi, P. (2017a). Language planning for Malay in Malaysia: A case of failure or success?, International Journal of the Sociology of Language, 244, 17-38.

Coluzzi, P. (2017b). The vitality of minority languages in Malaysia. Oceanic Linguistics, 56(1), 210-225.

Department of Statistics Malaysia (2016). Current Population Estimates, Malaysia, 2014 - 2016. Retrieved from https://www.dosm.gov.my/v1/index.php? $\mathrm{r}=$ column/ctheme\&menu_id=LOpheU43NWJWRWVSZkIWdzQ4TIhUUT09\&bu I_id=OWIxdEVoYIJCSOhUZzJyRUcvZEYxZz09.

Fishman, J. A. (1972). Language in sociocultural change. Redwood City, CA: Stanford University Press.

Gal, S. (1979). Language shift: Social determinants of linguistic change in bilingual Austria. London, UK: Academic Press.

Garrett, P (2010). Attitudes to language. Leiden: Cambridge University Press.

Ha, P.L., Kho, J., \& Chng, B. (2013). Nation building, English as an international language, medium of instruction, and language debate: Malaysia and possible ways forward. Journal of International and Comparative Education (JICE), 2(2), 58-71.

How, S. Y., Chan, S. H., \& Abdullah, A. N. (2015). Language vitality of Malaysian languages and its relation to identity. Journal of Language Studies, 15(2), 119-136.

Oakman, D. (2010). Facing Asia: A history of the Colombo Plan. Canberra: ANU E Press.

Pak, J. (2013, September, 2). Is Malaysia university entry a level playing field? BBC NEWS. Retrieved from http://www.bbc.com/news/world-asia-23841888

Sam, M. L., \& Wang, X. (2011). Ethnolinguistic vitality of minority communities in a multilingual society: A comparative study of the Chinese and Indians in Malaysia. Journal of Chinese Sociolinguistics, 2, 11-29.

Sato, T., \& Hodge, S. R. (2009). Asian international doctoral students' experiences at two American universities: Assimilation, accommodation, and resistance" Journal of Diversity in Higher Education 2(3), 136-148.

Saville-Troike, M. (2003). The ethnography of communication: An introduction (3rd ed.). Malden, MA: Blackwell Publishing.

Schiffman, H. F. (2010). South and Southeast Asia. In J. A. Fishman \& O. Garcia (Eds.), Handbook of language and ethnic identity: Disciplinary and regional perspectives (2 ed., Vol. 1, pp. 452-469). New York: Oxford University Press.

Sim, T. W. (2012). Why are native language of the Chinese Malaysians in decline. Journal of Taiwanese Vernacular, 4(1), 62-95. 
Smith, J. A., Flowers, P., \& Larkin, M. (2009). Interpretative phenomenological analysis: Theory, method and research. Thousand Oaks, CA: SAGE.

Tan, C.-B. (2000). Socio-cultural diversities and identities. In K. H. Lee \& C.-B. Tan (Eds.), The Chinese in Malaysia. Kuala Lumpur, Malaysia: Oxford University Press.

Tan, C.-B. (2004). Chinese in Malaysia. In M. Ember, C. R. Ember \& I. Skoggard (Eds.), Encyclopedia of diasporas : Immigrant and refugee cultures around the world (Vol. 2). New, York: NY: Kluwer Academic/Plenum.

Ting, S. H., \& Chang, Y. S. (2008). Communication in a close-knit extended Hakka family in Kuching, Sarawak: Mandarin or Hakka? Proceedings of $9^{\text {th }}$ Borneo Research Council (BRC), Borneo on the move: Continuity and Change, Kota Kinabalu, Malaysia.

Wang, X. (2010). The sociolinguistic realignment in the Chinese community in Kuala Lumpur: Past, present and future. Journal of Multilingual and Multicultural Development, 31(5), 479-489.

Wang, X., \& Chong, S. L. (2011). A hierarchical model for language maintenance and language shift: Focus on the Malaysian Chinese community. Journal of Multilingual and Multicultural Development, 32(6), 577-591.

Wang, X. (2012). Mandarin spread in Malaysia. Kuala Lumpur, Malaysia: University of Malaya Press.

Wang, X. (2017). Family language policy by Hakkas in Balik Pulau, Penang. International Journal of the Sociology of Language, 244, 87-118.

Wiersma, W., \& Jurs, S. G. (2009). Research methods in education : An introduction $\left(9^{\text {th }}\right.$ ed.). Boston, MA: Pearson.

Yin, R. K. (2014). Case study research: Design and methods ( $5^{\text {th }}$ ed.). Thousand Oaks, CA: SAGE.

Yow, C. H. (2013). Guangdong and Chinese diaspora: The changing landscape of Qiaoxiang. New York: Routledge. 